\title{
Dicho y no dicho durante la Guerra de Malvinas. Sobre las decisiones acerca de lo narrable, la supervivencia y una pequeña batalla altamente significativa pero que no figurará en las crónicas del conflicto de 1982
}

Said and unsaid during the war of Malvinas. On the decisions about what could be said, survival, and a small but highly significant battle that will not be in the chronicles of the 1982 conflict

\section{Federico Lorenz}

\section{(2) OpenEdition}

\section{Journals}

Electronic version

URL: http://journals.openedition.org/corpusarchivos/1028

DOI: 10.4000/corpusarchivos. 1028

ISSN: 1853-8037

\section{Publisher}

Diego Escolar

\section{Electronic reference}

Federico Lorenz, « Dicho y no dicho durante la Guerra de Malvinas. Sobre las decisiones acerca de lo narrable, la supervivencia y una pequeña batalla altamente significativa pero que no figurará en las crónicas del conflicto de 1982 », Corpus [En línea], Vol 2, No 1 | 2012, Publicado el 30 junio 2012, consultado el 10 diciembre 2020. URL : http://journals.openedition.org/corpusarchivos/1028 ; DOI : https://doi.org/10.4000/corpusarchivos.1028

This text was automatically generated on 10 December 2020. 


\section{Dicho y no dicho durante la Guerra de Malvinas. Sobre las decisiones acerca de lo narrable, la supervivencia y una pequeña batalla altamente significativa pero que no figurará en las crónicas del conflicto de $1982^{1}$}

Said and unsaid during the war of Malvinas. On the decisions about what could be said, survival, and a small but highly significant battle that will not be in the chronicles of the 1982 conflict

Federico Lorenz

\section{EDITOR'S NOTE}

Fecha de recepción del original: 17/04/2012. Fecha de aceptación para publicación: $21 / 05 / 2012$

A la memoria de los tripulantes del bote del Murrel, muertos en busca de comida durante la guerra de Malvinas: Alejandro Vargas, Pedro Vojkovic, Manuel Zelarayán y Carlos Alberto Hornos.

Donde estoy yo continúa todo tranquilo, las bombas caen muy lejos de nosotros y el fusil no lo usé nunca pero lo tengo en muy buenas condiciones, pero de eso no me gusta hablar. 
Néstor Sáenz, soldado conscripto, carta desde

Malvinas, 26 de mayo de 1982.

\section{La posibilidad}

1 El 8 de junio de 1982 amaneció soleado y calmo. "Día luminoso y de temperatura agradable", consigna el diario de guerra en Malvinas de la Brigada de Infantería Mecanizada X (Jofre y Aguiar 1987, p. 195). El sol salió a las 8:52 de la mañana, y hubo casi ocho horas de luz diurna. No llovió ni lloviznó, y las temperaturas alcanzaron los $7^{\circ}$ (Ejército Argentino 1983, Tomo II, Anexo 3.3). Con la cercanía del invierno, se trataba de un día atípico para los infantes que en algunos casos ya llevaban dos meses en las posiciones en los cerros alrededor de Puerto Argentino. Así había sido rebautizada la localidad de Puerto Stanley, capital de las islas Malvinas, desde el 2 de abril de ese año, cuando fuerzas conjuntas argentinas expulsaron a la guarnición británica de las islas, ocupadas por la fuerza desde 1833 y objeto de una disputa diplomática aún no resuelta desde entonces.

2 Esa mañana, en una de las posiciones argentinas del Regimiento de Infantería 7 (RI7), sus cuatro ocupantes estaban dedicados a la misma actividad: escribir cartas. Antonio Reda, un soldado conscripto que acababa de cumplir 20 años en las islas, bajaría junto con un compañero a colaborar en la descarga de provisiones en los galpones del Moody Brook, el cuartel de los Royal Marines devenido depósito y comando argentino. No tenían mucho tiempo. Así lo reflejan las cartas de sus compañeros de posición:

Hoy te escribo porque aprovecho que van 2 de los soldados que están en mi carpa. Perdoná la letra pero en realidad no veo mucho para escribir porque recién está aclarando y aparte estoy super incómodo para escribir (estoy adentro de la carpa y en este momento estamos los cuatro escribiendo) (Alberto Tarsitano, carta del 8/6/1982).

3 La posición de Reda y sus compañeros, una de las centenares cavadas o construidas por los soldados argentinos en Malvinas, estaba al norte del Monte Longdon, mirando a un arroyo llamado Murrel. Entre este y los soldados, había un río de piedra. No habían cavado un pozo, sino que se trataba de "cuatro paños armando una carpa debajo de una gran piedra para que el agua escurra por sus costados" (Antonio Reda, correo electrónico 18/10/2008). La roca los protegía tanto del viento como de la artillería. Como muchos otros soldados, al llegar a Malvinas encontraron que cuando cavaban, el agua afloraba enseguida, por lo que finalmente optaron por esa solución.

Esta carta va a ser muy sencilla ya que la estoy escribiendo muy apurado, porque dos flacos van a ir al pueblo y las van a llevar. No se cuándo les voy a volver a escribir porque de donde estamos no podemos bajar más (Héctor Píscopo, carta del 8/6/1982).

4 Para el 8 de junio, el regimiento de Reda llevaba casi dos meses en Malvinas. Habían llegado el 13 de abril y las diferentes compañías se habían dispersado en un amplio sector que iba desde la península de Cambers, pasando por el Wireless Ridge (una altura que estaba a las espaldas de la posición cuyos ocupantes se dedicaban febrilmente a escribir esa mañana) para llegar a la cresta oeste del Monte Longdon, que con poco más de 200 metros en su parte más alta, era una de las piezas centrales del esquema defensivo argentino. Aunque las posiciones del regimiento no estaban lejos de la población (unos 14 kilómetros los separaban de Puerto Argentino), el abastecimiento era muy escaso e intermitente. En muchos casos -y el del grupo de Reda era uno de ellos- en Malvinas los 
soldados quedaron librados a sus propios recursos: la "caza" de ovejas (por la que eventualmente podían ser castigados si se los descubría), el mercadeo o las bajadas clandestinas al pueblo para obtener comida. Las dificultades en el abastecimientos y la falta de un sistema logístico adecuado es un elemento más del elevado nivel de improvisación con el que fue planeada y conducida la guerra, y fue un elemento constitutivo de la experiencia bélica de miles de los combatientes destinados en las islas (Lorenz, 2012, p. 109 y ss).

5 Por eso la oportunidad de esa mañana no era para despreciar. Antonio Reda sabía que a cambio de ayudar en la carga y descarga de provisiones, los soldados podrían escamotear algunos comestibles. Así que terminaron las cartas, anotaron en un sobre las direcciones de todos -finalmente Reda bajaría solo - y emprendió la caminata de unas dos horas hasta los galpones del Moody Brook atravesando el terreno esponjoso y ondulante ${ }^{2}$.

El 8 de junio fue un día particularmente intenso y sangriento. Esa mañana, los británicos intentaron un desembarco al sur del dispositivo de defensa argentino en torno a Puerto Argentino, en Bahía Agradable. El cerco se estaba cerrando y la Task Force inició una operación para acelerar el emplazamiento de los efectivos que participarían en el ataque final sobre las defensas argentinas. Pero detectada por las avanzadas de los defensores, la fuerza de desembarco británica recibió el ataque de la aviación argentina. Dos transportes (Sir Tristram y Sir Galahad) y un lanchón de desembarco fueron gravemente averiados (el primero quedó fuera de combate y el segundo inutilizado. Un submarino, días después, remolcó el casco del Galahad hasta aguas abiertas, donde fue hundido y actualmente es una tumba de guerra); 51 hombres murieron y doscientos fueron heridos, mientras que tres aviones argentinos fueron derribados y sus pilotos murieron.

7 Pero para la mayoría de los soldados la guerra, hasta ese momento, no tenía esa espectacularidad, ni probablemente la tendría nunca. Había consistido, más bien, en una tensa espera bajo los bombardeos mientras las fuerzas atacantes se acercaban. El control del espacio aéreo por parte británica empeoró las duras condiciones, dificultó aún más el abastecimiento y empeoró las ya de por sí durísimas condiciones ambientales que enfrentaban los infantes argentinos; mientras que el bombardeo naval, aéreo y últimamente terrestre, así como la espera que parecía interminable, minaban el ánimo de muchos soldados y aumentaban la tensión ${ }^{3}$. Dos días antes las máximas autoridades militares de la X Brigada de Infantería habían visitado las posiciones del Regimiento de Infantería 6, parte del dispositivo de defensa de Puerto Argentino, no muy lejos de las posiciones del RI 7, y consignaron sus impresiones de este modo:

Con respecto al personal, ¿cuál era su espíritu? Según la opinión de los jefes, la tropa estaba un tanto afectada por la permanencia en el lugar. Los cuadros tenían conciencia de que el enemigo iba a atacar la posición, lo cual se deducía por el movimiento de sus helicópteros, la intensificación del fuego naval y de la artillería de campaña. De cualquier manera el personal se encontraba bien en cuanto a su espíritu, pero no más que eso (Jofre y Aguiar 1987, p. 191).

8 Estas eran las condiciones que vivían y percibían, entre otros miles, Antonio Reda y sus compañeros. En algunas líneas que intentó transformar en un diario personal, Reda escribió a mediados de mayo:

Por algunos días dejé de hacer este diario, ya que todo era monótono y rutinario hasta que el día $1^{\circ}$ de mayo a las 4.40 sentí un bombardeo y dieron el alerta rojo (ataque aéreo) y fuimos a ocupar nuestras posiciones juntamente con la otra mitad de la sección (...) 
9 A partir de aquí comenzaron a atacar paradójicamente los fines de semana con bombardeos aislados desde las fragatas o con aviones. Nosotros no podíamos comprender la actitud de ninguno de los dos países, y la pregunta más común es qué mal habíamos hecho para tener este castigo y por supuesto no tenía respuesta (Antonio Reda, diario personal, circa mayo 1982).

\section{La decisión}

10 Antonio Reda llegó a los galpones del Moody Brook. Recuerda un día soleado y tranquilo (debido a la meteorología favorable los aviones británicos bombardearan las barracas en dos ocasiones ese día, antes y después de la caminata de Antonio: una por la mañana y luego por la tarde). Reda transcribió la carta a su familia en el aerograma en blanco que le habían entregado ${ }^{4}$. Para hacerlo, se apoyó en la baranda del puente de madera que por entonces cruzaba el arroyo rumbo al pueblo:

Islas Malvinas 8-6-82

Estimada familia: Les escribo estas líneas para decirles que me encuentro perfectamente bien, espero que ustedes también lo estén y que tengan mucha fe y confianza. Por mi parte no hay grandes variantes.

Disculpen la demora en escribir, pero en estos días se nos hace un poco más difícil entregar las cartas.

Las últimas noticias que tengo de ustedes es un telegrama que recibí de Mary.

Hace unos cuantos días que no mando telegramas porque no pude ir hasta el pueblo.

Esta carta la escribo a la ligera porque tengo que entregarla, pero igualmente no tengo muchas cosas nuevas para contarles.

Muchos saludos para Angelita, Miguel, Javi, Doña Amalia y para todos.

Espero que papi y mami estén tranquilos y se cuiden. Saludos para Mario y la madre, cariños para toda la familia.

Avísenle a Mary que estoy bien, y que junto con esta va una carta para ella.

Les mando un fuerte abrazo y un beso grande para todos.

Chau hasta pronto

Tony. 8-6-82

11 Y redactó otra, muy similar para Mary, su novia (cruzar y duplicar la información para asegurarse la recepción también era una práctica frecuente en quienes pudieron enviar regularmente cartas) $)^{5}$ :

Islas Malvinas 8-6-82

Querida Mary: Antes que nada quiero decirte que estoy bien y así también espero que estés vos y los tuyos. Quedate tranquila y confiada porque yo también lo estoy.

Esta carta la escribo un poco apurado porque tengo poco tiempo para entregarla, y como hace unos cuantos días que no puedo mandar carta ni telegrama decidí hacerlo para tranquilizarlos. Te cuento que en los telegramas la única frase que podemos poner es esa, por eso es que son todos iguales [se refiere al hecho de que los mensajes que se podían enviar al Continente por esta vía sólo admitían un texto predeterminado].

Bueno, no tengo mucho para contarte porque acá las variantes no son muchas.

Avisá por mi casa y deciles que junto con esta va una carta para ellos.

Muchos cariños para todos, un beso grande para vos y toda tu familia.

Saludos para Néstor y Ale.

Espero que puedas controlar tus nervios y que seas siempre optimista.

Recibí el telegrama que me mandaste el día 20 aprox.

Bueno, me despido porque me están apurando para entregar la carta.

Chau, un beso grandote, cuidate y hasta pronto 
Tony. 8-6-82

12 Ambas cartas del 8 de junio desentonan en el conjunto de la correspondencia de guerra de Antonio: están escritas con mucha prolijidad, el papel está limpio, así como el dorso del aerograma, sin las marcas de tierra o barro que tienen otras.

Yo el 8 de junio estaba muy consciente de que no teníamos posibilidades, que los ingleses se venían y ya estaban muy cerca. Se veían sus movimientos de traslado de los pertrechos con helicópteros y nosotros estábamos en tan malas condiciones físicas que no podía dudar del resultado frente a un ataque. Ese día pude robar una caja de galletitas, me fui solo al pueblo. Mis compañeros ya no podían caminar, especialmente el Viejo y Gustavo. En definitiva vi que por una cosa (el enemigo) $u$ otra (nuestro Ejército) lo mas probable y lógico en esas condiciones era morir (Antonio Reda, correo electrónico del 26/9/2008).

13 Debido a esa asunción, Antonio Reda decidió "cuidar" a su familia al contarles sus experiencias. Al igual que muchas de las cartas que enviaron los soldados desde Malvinas, buscó llevarles tranquilidad. Para eso tenía que esforzarse por no enviar datos que permitieran inferir sus reales condiciones de vida, su malestar o su verdadero estado de ánimo. Y ejerció la autocensura, una de las prácticas habituales en muchos de quienes enviaron cartas desde algún frente de batalla (Lorenz 2008). En el caso de Antonio, esta voluntad estaba acentuada por su situación familiar. Sus papás tenían una salud delicada (su mamá había sido operada del corazón), y como hijo varón su trabajo era uno de los principales sostenes para la casa familiar de Ringuelet (afueras de la Plata). Ya al ser convocado para el servicio militar obligatorio había vivido el entrar bajo bandera como una verdadera complicación económica.

14 Las alusiones a esa necesaria "tranquilidad familiar" son frecuentes tanto en las cartas que recibía como en las que enviaba. Por ejemplo, en los primeros días, su novia le escribió:

Te pido por favor que te cuides mucho y que me escribas lo más rápido posible y me cuentes cómo estás no quiero que lo tomes mal pero si te pido que te cuides mucho es porque todos deseamos que vuelvas bien y sobre todo tu papá porque con todo esto si te pasa algo a vos le puede costar la vida a él (carta de Mary a Antonio Reda, 23/4/1982).

15 Además del deseo de que su novio volviera sano y salvo, la carta evidencia la escasez de elementos que los civiles involucrados en la guerra tuvieron para asumir la magnitud de lo que el conflicto implicaba, la grieta entre las distintas formas en las que el conflicto fue vivido. Esta brecha entre experiencias civiles y militares de la guerra fue una de las bases de las diferentes memorias elaboradas sobre el conflicto en la inmediata posguerra. A la vez, no eran sólo diferencias entre combatientes y no combatientes, sino también regionales. Así, la experiencia bélica no fue la misma para los patagónicos que para los porteños (Lorenz, 2010).

16 A la supervivencia en batalla, en las condiciones que venimos describiendo, Antonio debió agregar la preocupación por la salud de su padre, a quien "podía pasarle algo si algo le pasaba a él". Consciente de esta situación, Antonio se propuso hacer eso desde Malvinas. Por ejemplo, cuando por la radio que tuvieron en el pozo escuchó acerca del ataque británico a las Georgias, escribió:

Me decidí a escribirles para disminuir su preocupación ya que estuve escuchando radio (sobre todo las uruguayas) ${ }^{6}$ y les aconsejo que no les den bola a todo lo que dicen. Lo único cierto es el ataque a las Georgias, pero todavía no se conocen las consecuencias. 
Quiero decirles que me encuentro perfectamente bien de salud y que me estoy cuidando como me lo piden (carta de Antonio Reda a su familia, 28/4/1982). que vivía, reiteraba el pedido: "Voy a pedirles un favor, el más grande de todos, QUÉDENSE TRANQUILOS Y CONFIADOS porque así también lo estoy yo" (carta de Antonio Reda, 24/5/1982) y rescataba la forma en la que la guerra hacía revalorizar las cosas como una forma de comprometerse a regresar:

Cambiando de tema te digo que la guerra, como vos te imaginás, no sirve para nada, lo único que te hace ver es que las pequeñas cosas de la vida, pero las más pequeñas, son las que hacen hermosa la vida así que disfrútenla! Sin amargarse porque pronto lo haremos todos juntos" (Carta de Antonio Reda, 24/5/1982).

\section{La batalla de los ratones ${ }^{7}$}

Antonio volvió del cuartel de Moody Brook con un botín inesperado que compartió con sus compañeros de posición: un paquete de galletitas con el que logró entusiasmar a Pipo, uno de ellos, para repetir la expedición en busca de comida uno o dos días después. Hacia el 8 de junio, los galpones de las antiguas barracas de los Marines estaban parcialmente abandonados y derruidos, debido a los bombardeos británicos ${ }^{8}$. El 11 de junio, finalmente, "a las 16.00 Moody Brook fue atacado por aviones que lograron impactos directos sobre el edificio, resultando dos soldados muertos, uno herido y uno desaparecido" (Jofre y Aguiar 1987, p. 207) ${ }^{9}$

Sin embargo, al regresar de enviar las cartas, al día siguiente (9 de junio), Antonio tuvo que desempeñar una tarea infinitamente menos grata que la de recoger comida. La tarde anterior, un grupo de soldados de la compañía A del Regimiento 7 había cruzado el Murrel rumbo a la casa de unos isleños donde habitualmente iban a buscar comida, abrigo y eventualmente higienizarse. Para pasar utilizaban un bote, que debían orientar cuidadosamente ya que las orillas de la corriente de agua habían sido minadas por los argentinos. Esa noche, probablemente debido a la niebla, se desorientaron, y uno de ellos pisó una mina antitanque mientras llevaban el bote a cuestas. Murieron cuatro de los cinco soldados que salieron esa tarde con autorización de sus superiores: Alejandro Vargas, Pedro Vojkovic, Manuel Zelarayán y Carlos Alberto Hornos.

A la mañana siguiente, un cabo $1^{\circ}$ llamó a " 16 soldados con cuatro frazadas". Antonio se presentó entre los primeros, porque cuando la llamada era de ese tipo era para buscar víveres, y "en esa estaba en todas" (entrevista a Antonio Reda, 14 de octubre de 2008). Sin embargo, esta vez tuvo que levantar los restos de sus compañeros y llevarlos a los galpones del Moody. Recuerda el panorama que se encontró al llegar a las orillas del Murrel, no así qué hicieron luego con los restos, dónde los dejaron, quién los condujo finalmente al pueblo.

21 Fue poco después de ese incidente que Antonio consiguió bajar con Pipo al Moody Brook una vez más. Como señalamos, lo convenció gracias al "señuelo" que había encontrado cuando bajó a enviar las cartas: "por eso para mí tuvieron tanta significación las galletitas (...) Fue como demostrar que podíamos seguir buscando alternativas para comer y así al volver con ellas fue que estimuló a Pipo a arrancar conmigo" (Antonio Reda, correo electrónico del 8/10/2008).

22

El grupo de Antonio estaba en muy malas condiciones físicas y anímicas: "el Viejo" ya estaba imposibilitado de moverse, Gustavo estaba muy deprimido (Antonio le ofreció en 
broma varias veces una pistola para que "terminara", ante su queja permanente), y sólo Antonio y Pipo se movilizaban cada tanto. Antonio, uno de los más activos, perdió más de veinte kilos de peso mientras estuvo en Malvinas.

Llegaron a los galpones y los encontraron abandonados, prácticamente vacíos y en ruinas. La desilusión fue muy grande, pero en los edificios ruinosos encontraron restos de comida por el piso, mezclados con bolsas rotas, y se dedicaron a recogerlos.

De repente, de entre unas bolsas de arpillera salieron varios ratones que estaban comiendo unas frutas secas. Enfrentar a los roedores les hizo reír pero también tomar conciencia del grado de postración en que se encontraban: "Estos hijos de puta nos van a comer las cosas", gritó uno de ellos mientras ahuyentaban a los pequeños ratones. Las frutas y los porotos recogidos del piso ese día los sostuvieron hasta el final.

En la noche del 11 de junio, el Segundo Batallón de Paracaidistas británico (Para 2) atacó el Monte Longdon. Se produjo uno de los combates más sangrientos de la guerra, pero para el amanecer del 12 de junio los argentinos fueron desalojados del monte. La compañía de Antonio quedó en la primera línea de combate, aunque los británicos no avanzaron de inmediato, sino que se reagruparon mientras esperaban refuerzos. Aunque habían sido sorprendidos por la dureza de la resistencia, los ingleses sabían que la derrota de los argentinos era una cuestión de tiempo.

Desde sus posiciones, los soldados argentinos veían los movimientos de los británicos en el cerro donde habían combatido sus compañeros, mientras el cañoneo argentino y británico caía intermitentemente sobre las posiciones de ambos bandos y se producían intercambios aislados de disparos. Al mediodía del 12, Antonio, a los gritos, le propuso al Sapo, un compañero que estaba en otra posición cercana, cambiarle "leche en polvo por unos cigarrillos". La respuesta fue un morterazo británico que cayó entre los dos: le arrancó parte de la oreja al Sapo, e hirió a Antonio en la pierna, atrapado en medio del salto en busca de refugio que había dado cuando escuchó el ruido de salida del proyectil.

Al principio, Antonio siguió moviéndose como si nada, pero a medida que el cuerpo se le enfrió, le resultó cada vez más difícil caminar. Lo enviaron a la retaguardia junto con otro compañero herido, con los ojos completamente vendados, para que se acompañaran y asistieran en el regreso: serían respectivamente las piernas y los ojos del otro.

Luego de pasar unas horas en el Hospital de Puerto Argentino, Antonio Reda fue embarcado en uno de los últimos vuelos al Continente, el día 13 de junio. En uno de sus bolsillos llevaba una bolsa plástica que había contenido arroz, y ahora protegía de la humedad y la suciedad las cartas recibidas en las posiciones. Entre ellas también estaban las cartas que había escrito y transcripto con prolijidad para su familia apoyado en el puente del Moody Brook la mañana luminosa del 8 de junio.

29 Antonio nunca las envió. En un primer momento, Reda quiso "proteger" a su familia y a su novia, enviándoles un mensaje tranquilizador a pesar de considerar que no tendría salvación, y ocultándoles la dura realidad que vivía en las islas. Pero luego lo pensó un poco más, y esa misma certeza hizo que decidiera que ese gesto no valía la pena, que además sería contraproducente:

Yo lo que tengo en mi mente es estar arriba de este puente de madera que no sé por qué cuernos lo reservo así en mi memoria y tener una reflexión como decir "Esto es al pedo" y... No tiene sentido. Si yo ya estaba viendo el Moody Brook destruido, que estaban abandonando las posiciones propias, más replegarse del Moody Brook (...) Lo que pensaba en el fondo era que la carta iba a llegar y yo iba a estar muerto y eso era peor. Porque una vez estando muerto les llega la carta, les hace creer que estoy 
vivo. O sea, yo decía, si me salvo... si no me salvo bueno, acá se terminó la historia, ya está. Para qué seguir agregándole más recepción de cartas, cosas... cuando sabés que se termina, para un lado y para el otro, no tiene sentido la última carta (Antonio Reda, entrevista, 14/10/2008).

Así, las cartas regresaron al Continente sin ser enviadas, y si sabemos qué sucedió después de ese día 8 de junio de 1982 en la vida de un simple soldado argentino en Malvinas, es porque Reda sobrevivió a una guerra que consideraba perdida.

\section{La complejidad de la Historia}

31 Algunas reflexiones en torno a esta pequeña historia personal nos permiten insistir una vez más en la importancia de los testimonios orales, dentro de su necesario diálogo con otras fuentes, recursos y preguntas. Por extensión, pensar algunas cuestiones relativas a la historia reciente y su escritura, y dentro de este marco, sobre la atención prestada a la guerra de Malvinas dentro de ese campo.

En primer lugar, si Reda hubiera despachado las cartas y muerto después (por ejemplo a manos del morterazo británico del 12 de junio), esa correspondencia expresaría "sus últimas palabras"10. Como la autocensura lo llevaba a esconder muchas de sus impresiones, no conoceríamos sus estados de ánimo en las islas, ocultos por las líneas garabateadas en una carpa y transcriptas en el puente de Moody Brook, guiadas por la voluntad del engaño tranquilizador, ni en su testimonio, libre de la presión de esos años.

Más aún, por la fecha en la que fueron escritos, los aerogramas no hubieran dado cuenta de las experiencias de guerra más fuertes de Antonio Reda en Malvinas: la voladura de sus compañeros, la recolección de sus cadáveres, la sensación de lo irrisorio de su estado físico al combatir contra los ratones en el Moody por comida (lo que funciona en su relato como metáfora de las condiciones en las que combatió), y el momento en el que lo hirieron. Tampoco sabríamos nada de la ambigua sensación del alivio por la evacuación y la culpa por abandonar a sus compañeros allí, en vísperas del combate final, que dan cuenta de algunos de los lazos construidos entre los hombres que combatieron en Malvinas. Expresado de una manera muy gruesa, si el último testimonio de Antonio Reda hubiera sido los documentos escritos, probablemente habríamos sido tan "engañados" o "tranquilizados" por esas "fuentes" como sus destinatarios de 1982.

Antonio, afortunadamente, sobrevivió a la guerra. Esto es una suerte también para los historiadores, que cuentan con la posibilidad de estudiar las cartas que decidió no enviar y contrastarlas con el testimonio de su redactor. Porque lo que da densidad a una historia que podría haber sido mucho más simple es la pregunta al testigo, la posibilidad de construir su testimonio y ponerlo en diálogo con los contextos más amplios de la guerra y con otras fuentes que produjo durante el desarrollo de los acontecimientos evocados en una entrevista.

A partir de una mención fortuita a la "batalla de los ratones" en el Moody Brook durante un asado que compartimos, entre Antonio y yo comenzó un intercambio de preguntas que resultó en correos electrónicos, entrevistas y la recolección de la correspondencia de guerra no sólo de Reda, sino de sus compañeros de posición. Fueron y vinieron correos aportando preguntas, respuestas y fotos para ordenar esos pocos días y horas que iban entre la carta y la salida de Antonio de Malvinas y que ordenaron la cronología de los hechos vividos por Reda. Como resultado, Antonio pudo establecer la secuencia de una 
serie de acontecimientos muy intensos en su vida desarrollados entre el 8 y el 13 de junio, que hasta ese momento tenía superpuestos o confusos.

Mucho se ha escrito, se discute y se discutirá sobre el predominio de los testimonios orales en la reconstrucción del pasado argentino, sobre sus características falibles, poco confiables y volubles al impacto de la memoria. Algunos autores incluso se han preguntado sobre el carácter determinante que su predominio ha tenido en las formas en las que nos relacionamos con el pasado. En algún sentido, en esta historia la carga es la inversa: lo incompleto, lo "falso" y sesgado es el documento escrito, las cartas, que resultan tan poco confiables como la palabra orientada por la memoria más de un cuarto de siglo después de la guerra.

Esta afirmación no busca volcar el fiel de la balanza hacia las fuentes orales. Nada es tan simple. La riqueza de la historia de Antonio Reda y sus cartas está en que su testimonio y su correspondencia de guerra se unen para mostrar una vez más la idea de que deben ser manejadas cuidadosamente todas las fuentes históricas, con los recaudos particulares a sus características en cada caso, ya que todas están sometidas a la subjetividad de los autores, a su contexto histórico de producción.

Pero, también, al momento en el que son sometidas a la crítica histórica, ya que arrojan el desafío acaso más cautivante que encierra el estudio de la historia reciente: la convivencia del historiador con los actores del proceso que investiga. Este hecho no solo es un desafío metodológico, sino también epistemológico. La "aceleración" del tiempo histórico que hace que convivamos con los hechos que historizamos no debería ni acomplejarnos ni hacernos apelar a ningún principio de autoridad. Es una posibilidad de redimensionar la magnitud del problema de la legitimidad para hablar sobre el pasado, es decir: que hay unas voces supuestamente más autorizadas para interpretar y escribir la Historia que otras. De allí que debe impulsarnos a desarrollar más y mejores herramientas que nos permitan dar cuenta críticamente de dicha complejidad.

Los actores, como nos recuerda el mismo Reda, no sólo eligen qué contar, sino cómo, así como también, acaso inconscientemente, el momento para producir esa narración, para hacerla pública:

El día que dejé de escribir el diario fue por lo mismo, ya tenia la sensación de que si salía vivo lo contaba entonces ¿para que escribir? (Antonio Reda, correo electrónico del 26/09/2008).

En el campo de la historia reciente, en muchos casos los historiadores somos tan actores como nuestras "fuentes vivas". ¿Por qué deberíamos entonces pensar que procedemos de otro modo quienes nos aproximamos al pasado con fines de reconstrucción crítica? En este caso, son los papeles rescatados de la guerra cuidadosamente preservados, junto al recuerdo fragmentario y desordenado de los actores y las preguntas del historiador, los que pueden aportar a una reconstrucción más completa y humana de la Historia. Las aproximaciones a la guerra de Malvinas desde la historiografía post dictatorial han estado por demás atravesadas por estos problemas y limitaciones, demasiado parecidas a la auto represión de Reda desde las islas (Lorenz 2011).

41 En Los desnudos y los muertos, Norman Mailer cuenta la historia de Gallagher, el infante estadounidense que durante la Segunda Guerra Mundial recibe en Anopopei, en el lejano frente del Pacífico, la noticia de que su mujer ha muerto al dar a luz. A miles de kilómetros de sus hogares, las cartas permitían establecer extrañas relaciones con los seres queridos. Gallagher recibió la noticia, y 
...después de un rato se calmó y se puso a mirar sus cartas. La noche anterior había tenido tiempo de leer solamente las de su mujer. Todas eran cartas antiguas. La más reciente era de hacía un mes, y no dejaba de decirse, sorprendido, que tal vez ya fuera padre. La fecha probable que había mencionado su mujer para el nacimiento de la criatura ya había pasado, pero él no podía creerlo. Siempre se imaginaba que lo que ella escribía ocurría el mismo día en que él leía la carta; si ella decía que iba a visitar a una de sus amigas al día siguiente; él pensaba que Mary haría la visita el día después de leer la carta. La razón le advertía de su error, pero su mujer seguía viviendo para él solamente en el instante en que leía sus cartas (Mailer 2008, 264).

Sucedió algo terrible. Debido al retraso en las comunicaciones, después de la noticia del fallecimiento, comenzaron a llegar cartas con posterioridad a la fecha de la muerte su esposa. Gallagher reaccionó con alegría. Este delay le hacía sentir que su esposa seguía viva:

Durante meses había sabido de la vida que llevaba su esposa sólo a través de cartas y la costumbre estaba tan arraigada que no podía desprenderse de ella. Empezó a sentirse contento; esperaba las cartas como siempre había hecho y pensaba en ellas por la noche antes de dormirse. Sin embargo, después de unos días, comprendió algo espantoso. La fecha de parto se acercaba cada vez más, habría una carta final, y ella estaría muerta (Mailer 2008, p.284).

Sus jefes y compañeros de pelotón discutieron qué hacer frente a ese "autoengaño". ¿Debían seguir entregándoles las cartas y fomentar su "locura" o no? Pero ante la mera insinuación, la respuesta de Gallagher fue tajante: "Si no me dan las cartas, ella se va a morir" (Mailer 2008, p.285).

Al estudiar la guerra de Malvinas, breve e intensa, la exploración de la correspondencia enviada y recibida por los argentinos atravesados por el conflicto reactualiza la belleza literaria de la trágica historia de Gallagher. Hay cosas que siguen vivas allí. Las cartas comparten su anacronismo con las fotografías. Las palabras fijas en el papel han detenido el tiempo, tanto como la imagen ha congelado un gesto o una mirada. Allí hay un punto en común con la extrañeza que produce la voz presente en el hoy del que evoca algo sucedido hace treinta años.

Las cartas escritas por los argentinos durante la guerra contra los británicos escaparon, en líneas generales, a la censura institucional. Producidas en un conflicto breve, se parecen a aquellas escritas en los momentos iniciales de otros enfrentamientos armados, cuando la censura castrense estaba en proceso de implementación al paso que las maquinarias bélicas afianzaban sus mecanismos y los frentes se estabilizaban.

Las cartas arrojan entonces preguntas -y respuestas dadas por quienes las escribieron-a cuestiones centrales para avanzar en la comprensión de un hecho histórico decisivo del último cuarto del siglo XX argentino. Laten en las líneas de trazos infantiles y toscos, o en aquellas saturadas de solemnes giros patrióticos, los porqués de los hombres enviados a combatir y sus familias, ante la inminencia de alguna hora decisiva, o enfrentando el tedio interminable de la vida en las posiciones; sus deseos y esperanzas, en muchos casos sus enojos, frustraciones y odios. Escaparon a la destrucción y a las censuras de entonces, resisten a las de este presente y en muchos casos aguardan.

Y si bien hay diferencias y distorsiones en las expectativas y valoraciones sobre la guerra, por ejemplo entre los oficiales, suboficiales y conscriptos, emergen no obstante de entre las líneas escritas entre abril y junio imágenes para entender todo un sistema de valores llevado a un clímax por el hecho bélico. Son insinuaciones de un mundo cultural y político 
mucho más complejo y diverso, regional y experiencialmente, del que suelen dar cuenta las lecturas políticas e historiográficas predominantes sobre el conflicto.

Por supuesto que no se trata de leer literalmente lo que las cartas dicen, o lo que los sobrevivientes recuerdan. La historia de Antonio Reda es una advertencia al respecto tanto como una invitación a poner en diálogo las diferentes fuentes que aportan a la comprensión del pasado reciente. Acaso porque a la hora del final de una vida no existan las últimas cartas o las últimas palabras, sino más bien últimas preguntas, ese abandono del campo de batalla.

\section{BIBLIOGRAPHY}

Adler, B. (Ed.). (2003). War letters from Vietnam. New York: Presidio Press.

Balza, M. (2003). Malvinas. Gesta e incompetencia. Buenos Aires: Atlántida.

Camogli, P. (2007). Batallas de Malvinas. Buenos Aires: Aguilar.

Clarke, G., Ghisiglieri, J. y Sarno, A. (2008). Palabras de Honor. Relatos de vida de soldados ex combatientes de Malvinas. La Plata: Instituto Cultural de la Provincia de Buenos Aires. Archivo Histórico "Dr. Ricardo Levene".

Housman, L. (Ed.). (2002). War letters of fallen Englishmen. Philadelphia: Pine Street Books. Jofre, O. y Aguiar, F. (1987). Malvinas. La defensa de Puerto Argentino. Buenos Aires: Sudamericana. Ejército Argentino (1983). Condiciones meteorológicas en Puerto Argentino. En Informe Oficial Conflicto Malvinas. Tomo II, Anexo 3.3. Buenos Aires: Ejército Argentino.

Lorenz, F. (2011). El malestar de Krímov. Malvinas, los estudios sobre la guerra y la historia reciente argentina. Estudios, 25 (Enero-Junio 2011), 47-65. Córdoba: Centro de Estudios Avanzados de la Universidad Nacional de Córdoba.

Lorenz, F. (2008, mayo-agosto). “Es hora que sepan”. La correspondencia de la Guerra de Malvinas: Otra mirada sobre la experiencia bélica de 1982. Revista Páginas. Revista digital de la Escuela de Historia. [On line], 1. Disponible en: www.revistapaginas.com.ar Lorenz, F. (2012). Las guerras por Malvinas. 1982-2012. Buenos Aires: Edhasa.

Lorenz, F. (2010). Otras marcas. Guerra y memoria en una localidad del sur argentino (1978-1982). En Ernesto Bohoslavsky et alii (Comp.), Problemas de historia reciente del Cono Sur. Buenos Aires: Prometeo Libros. Volumen I.

Mailer, N. (2008). Los desnudos y los muertos. Barcelona: Anagrama.

Speranza, G. y Cittadini, F. (2006). Partes de guerra. Buenos Aires: Edhasa.

Vargas, S. (2005). Malvinas. Historias breves y sentimientos. Buenos Aires: Dunken. 


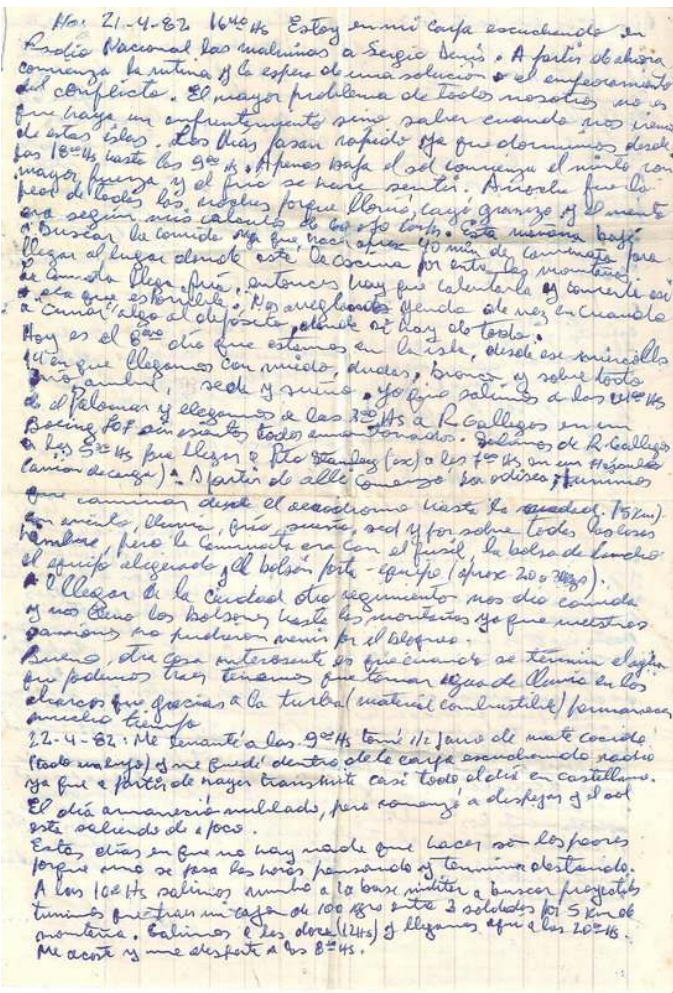

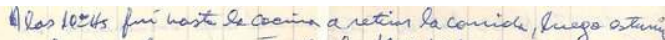

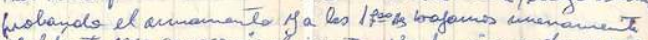

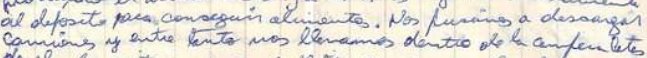

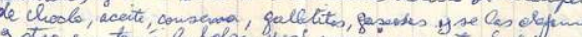

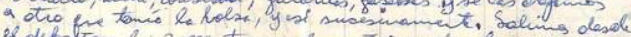

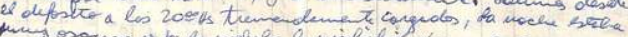

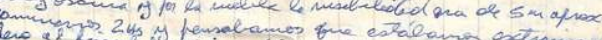

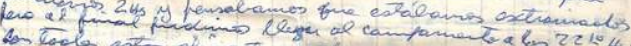

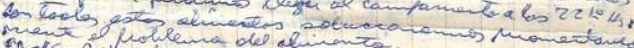

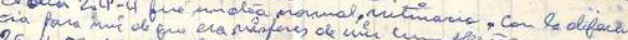
ariento sur ob a las 4100 ts comeng a llower y a soplar

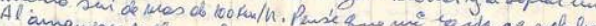

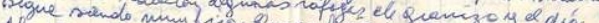

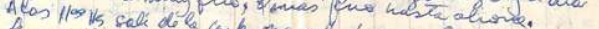

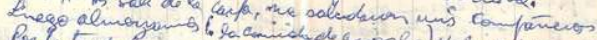

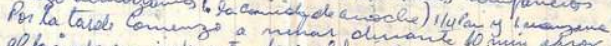

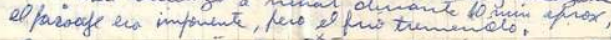
Por algunos dias dy of hacer este diaris, fa fru toils

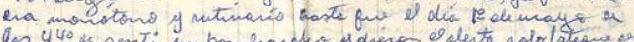

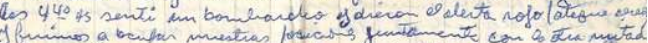

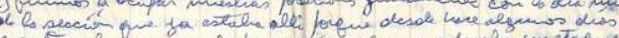

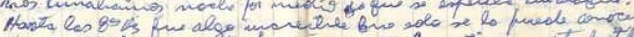

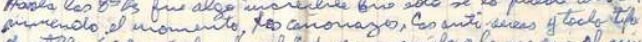

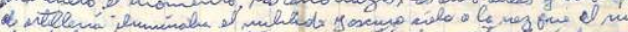

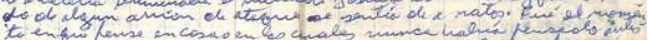

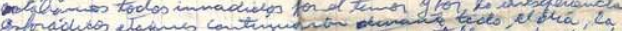

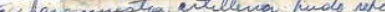

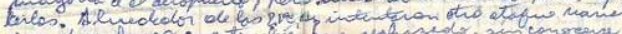

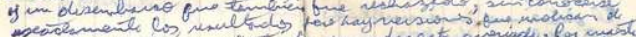

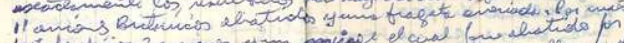

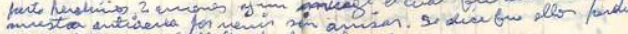

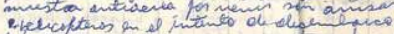

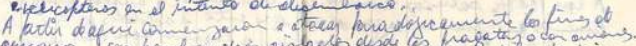

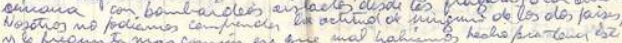




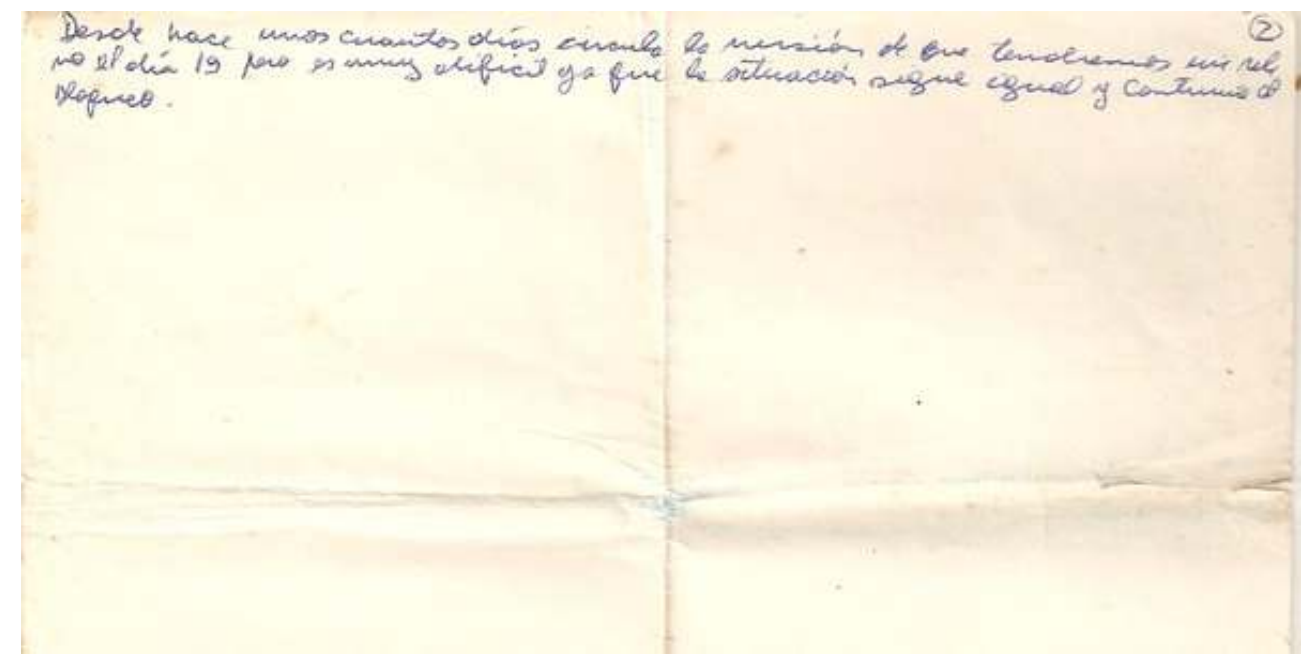

Diario Personal. Hasta el comienzo de los bombardeos, Antonio llevó un diario de sus experiencias en Malvinas. Nótese la minuciosidad de la descripción, y el contraste entre la "voluntad de contar" del inicio y las últimas líneas.

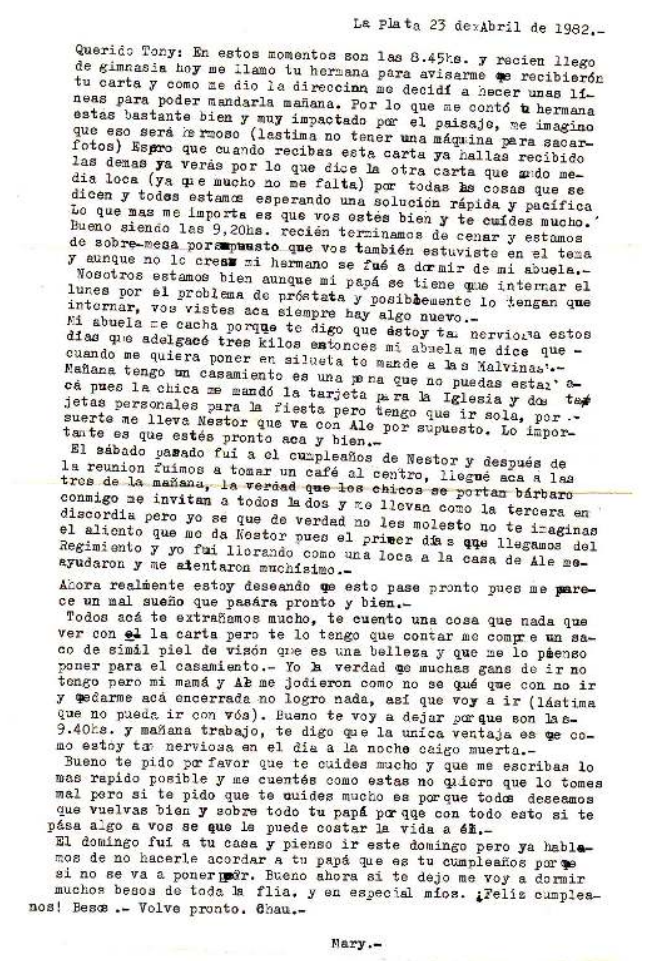

Carta de Mary, novia de Antonio Reda, 23 de abril de 1982. 


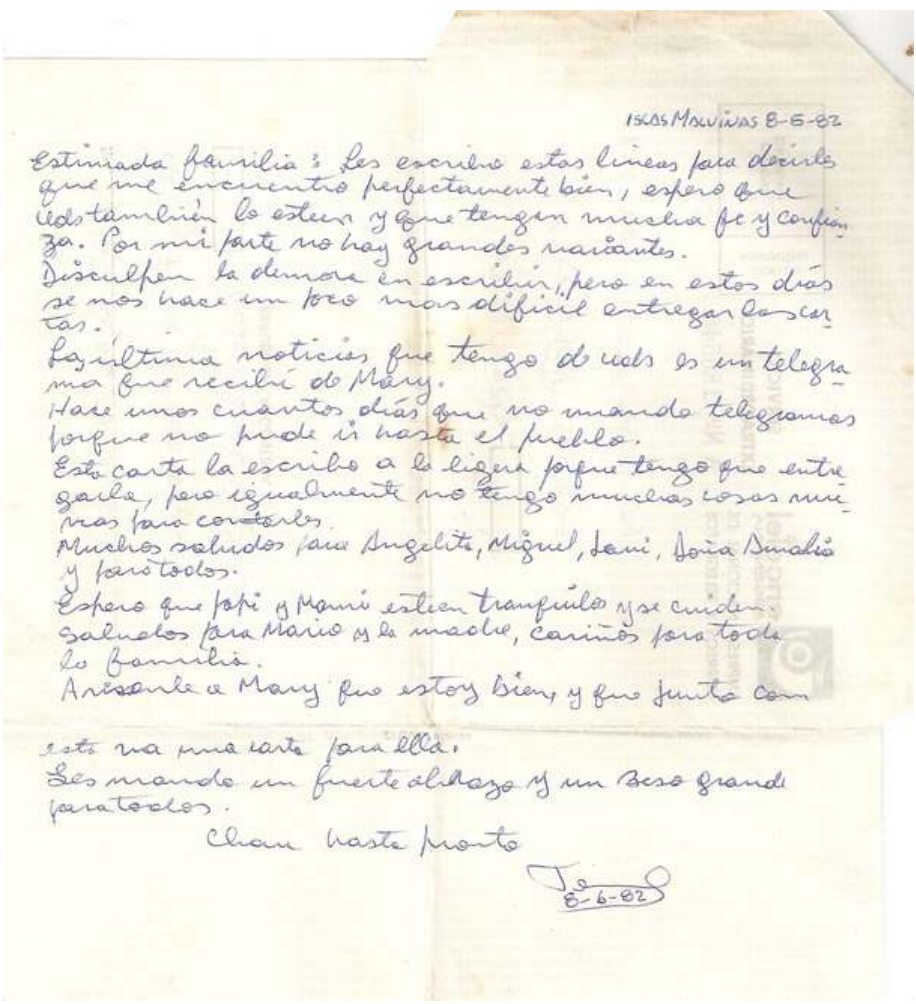

Carta del 8 de junio de 1982, que Antonio no llegó a enviar, en la que disimulaba sus condiciones reales de vida para no alarmar a sus familiares. 


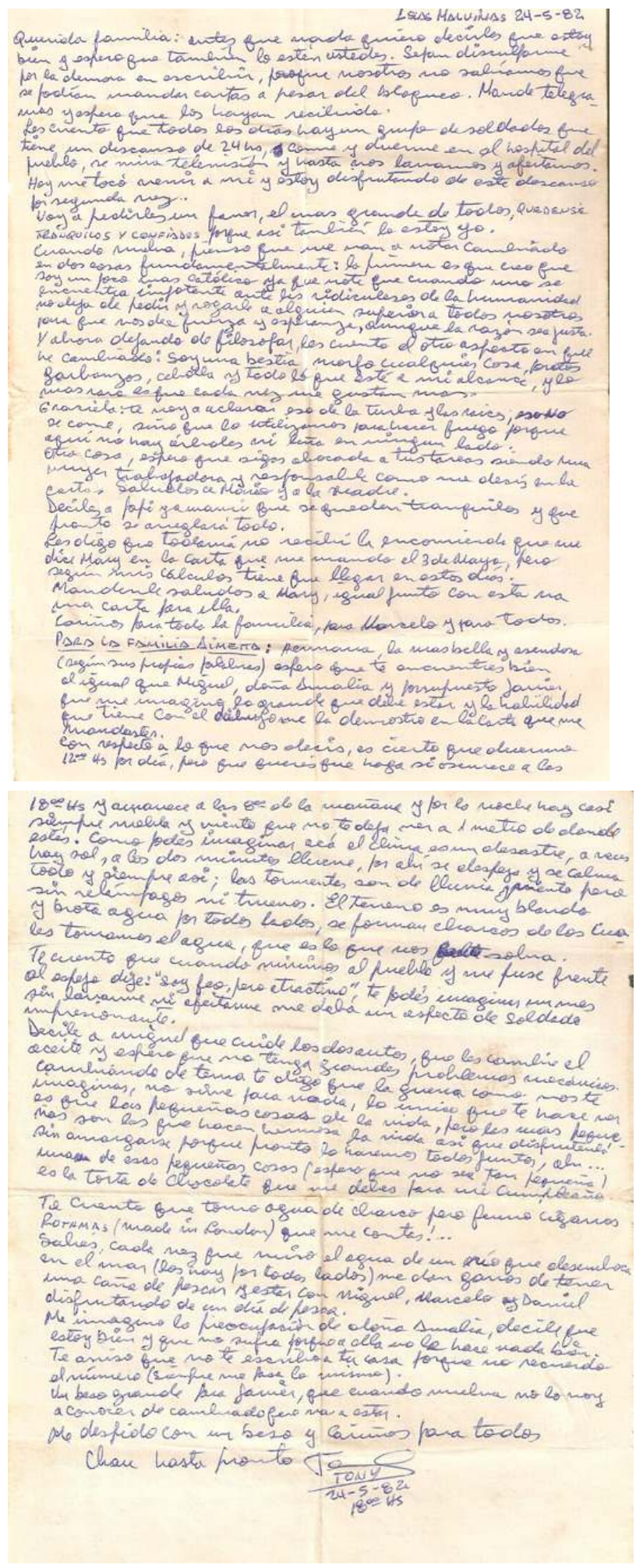

Carta de Antonio del 24 de mayo, en la que pide a su familia tranquilidad y confianza. 

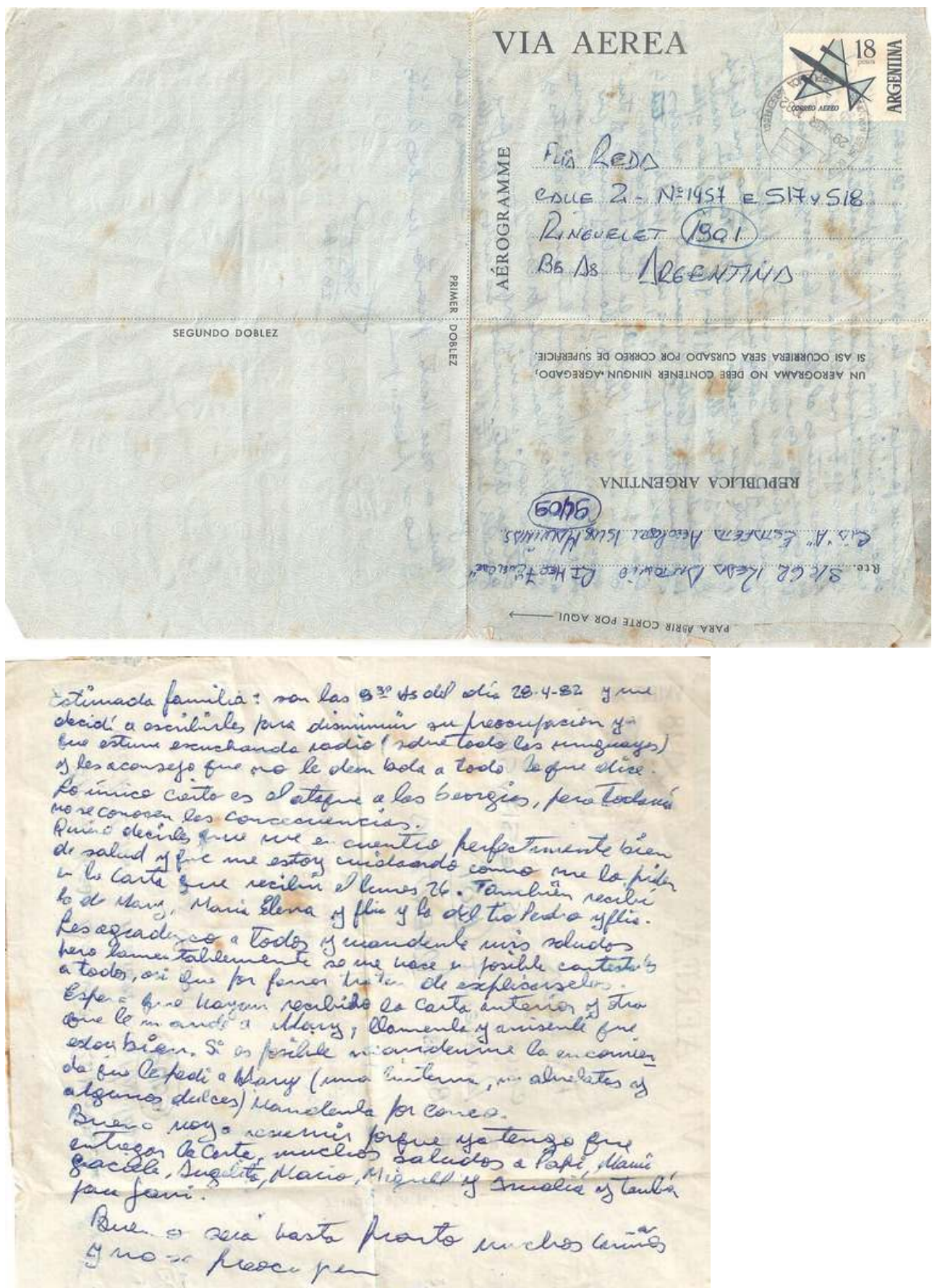

Reverso y anverso de la carta en la que Antonio, el 28 de abril, aporta novedades y tranquiliza a su familia acerca de la vida en las islas. El sobre era provisto oficialmente a los soldados para el envío de cartas desde Malvinas. 


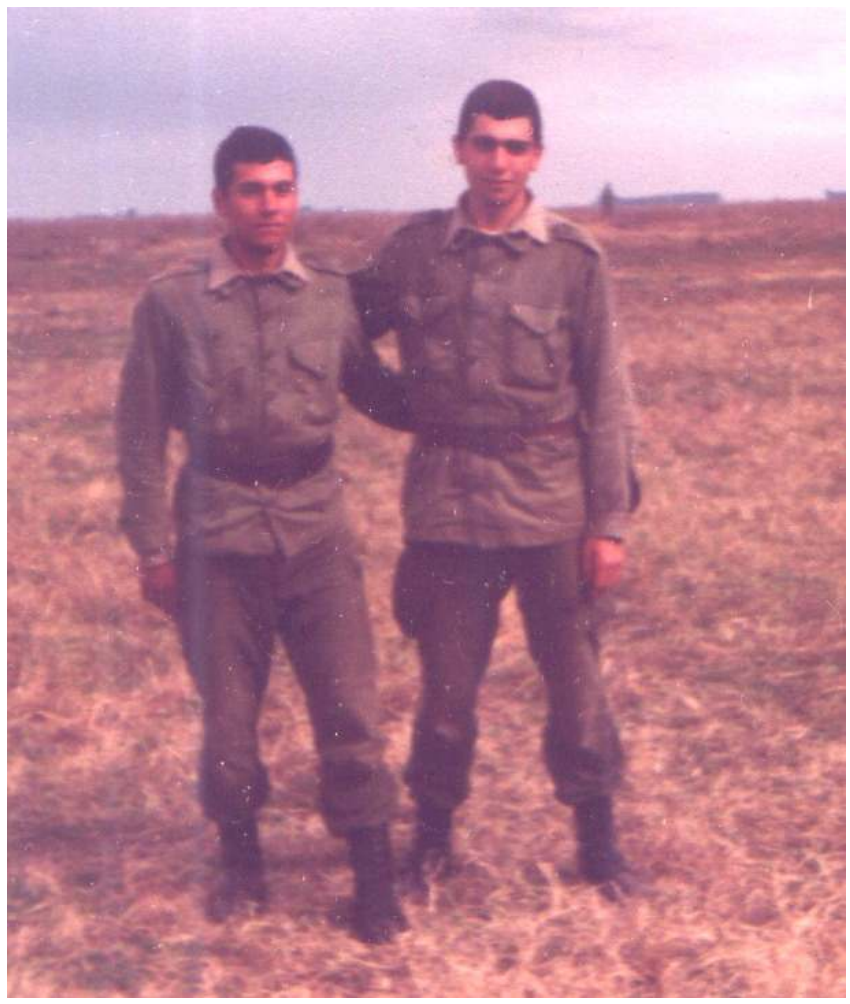

Antonio en 1981, durante los ejercicios realizados en Monte, provincia de Buenos Aires, como parte del servicio militar obligatorio. A su derecha su amigo Víctor Ramírez, muerto en Malvinas.

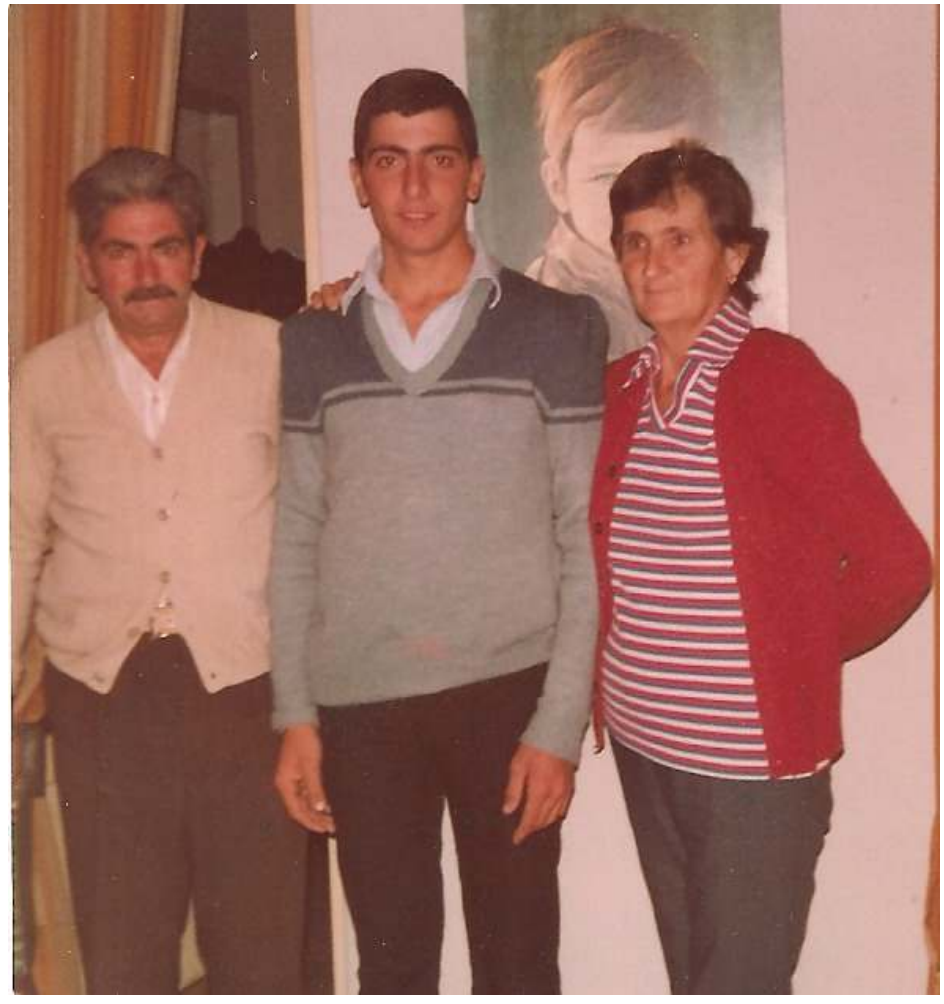

Antonio junto a sus padres en julio de 1982, a un mes de su evacuación de las islas. 


\section{NOTES}

1. Agradezco la paciencia de Antonio Reda ante mis preguntas y requerimientos, que fueron y serán muchos. También las lecturas críticas y sugerencias de Juan Bautista Duizeide, Sandra Gayol, Anne Pérotin-Dumon y Andrea Rodríguez, así como las de los evaluadores anónimos de este texto.

2. La reconstrucción de los sucesos que siguen, en base a intercambios de correo electrónico con Antonio Reda, y entrevista del autor del 14 de octubre de 2008. Asimismo, se pueden consultar Guillermo Clarke, Juan Ghisiglieri y Alicia Sarno, Palabras de Honor. Relatos de vida de soldados ex combatientes de Malvinas, La Plata, Instituto Cultural de la Provincia de Buenos Aires. Archivo Histórico “Dr. Ricardo Levene”, 2008.

3. Ver Balza 2003, Camogli 2007, Speranza y Cittadini 2006 y Lorenz 2012.

4. Un aerograma es un envío postal aéreo, en un formato estándar, en el que el dorso de la carta, plegado, hace las veces de sobre.

5. Antonio se casó con Mary, con quien tiene una hija.

6. Los motivos para escuchar radios uruguayas podían ser dos: uno, el hecho de que eran mejor recibidas desde las islas; el otro, que se prefiriera ese canal por considerarlo más "veraz" que las informaciones propias, en tanto reproducían información internacional.

7. La narración que sigue, en base a entrevista a Antonio Reda, 14 de octubre de 2008, intercambio de correo electrónico antes referido, Palabras de honor, op.. Cit y Vargas 2005.

8. Actualmente, de los galpones sólo queda un playón de cemento: no sobrevivieron al cañoneo de ambos bandos de abril y junio de 1982. El puente de madera del Moody también fue reemplazado por una construcción más moderna pero existen fotografías de tiempos de guerra.

9. Existe una filmación, producida el día anterior, en donde se ve una entrevista a uno de los conscriptos muertos en el ataque, el soldado Mosto.

10. Existen numerosos antologías de "últimas cartas" escritas por soldados, sobre todo desde la Primera Guerra Mundial. Era a la vez una práctica habitual de muchos combatientes, ante la inminencia de un combate importante en el que aumentaba el riesgo de perder la vida. Por ejemplo: Bill Adler (editor) War Letters from Vietnam, New York, Presidio Press, 2003 y Laurence Housman (editor), War Letters of Fallen Englishmen, Philadelphia, Pine Street Books, 2002

\section{ABSTRACTS}

The article focuses on the experience of the Argentinean soldiers during the Malvinas/Falklands War (April-June 1982). It studies war correspondence sent and received by a soldier during the conflict, and the oral testimony produced more than 25 years later by him. It focuses on three elements of the Malvinas war experience: relations with the civilians (family, friends, girlfriend), the difficult conditions under which the soldiers were sent to fight, and combat and confrontation with death. The article poses some challenges for the social history of war and methodological issues in recent history.

El artículo se concentra en la experiencia de los combatientes argentinos durante la guerra de Malvinas (abril-junio 1982). Estudia la correspondencia de guerra enviada y recibida por un 
soldado durante el conflicto y el testimonio oral producido más de un cuarto de siglo después. Se concentra en tres elementos constitutivos de la experiencia bélica de Malvinas: las relaciones con los civiles (familia, amigos, novia), las difíciles condiciones en las que los soldados fueron a combatir, y la confrontación con la lucha y la muerte. Plantea algunos desafíos para la historia social de la guerra y cuestiones metodológicas relativas a la historia reciente.

INDEX

Keywords: Malvinas, Falklands, war, experience, war letters

Palabras claves: guerra, experiencia, cartas de guerra

AUTHOR

FEDERICO LORENZ

IDES - CONICET. Correo electrónico: federicoglorenz@gmail.com 